\title{
Pengaruh Kualitas Pelayanan Food and Beverage Department Terhadap Kepuasan Konsumen Hotel Daily Inn Jakarta
}

\author{
Herlina $^{\text {a,1,* }}$, Lila Muliani ${ }^{\text {b,2 }}$ \\ ${ }^{a}$ Prodi Hospitaliti dan Pariwisata, Institut Stiami, Jakarta \\ ${ }^{\mathrm{b}}$ Prodi Hospitaliti dan Pariwisata, Institut Stiami, Jakarta \\ ${ }^{1}$ herlina_stiami@yahoo.co.id *; ${ }^{2}$ lilamuliani@gmail.com \\ * corresponding author
}

This study aimed to analyze the effect of the food and beverage department service quality on customer satisfaction at the Daily Inn Hotel, Jakarta. This study used a quantitative method with a data collection technique in the form of questionnaires and literature studies. The population of this study was the consumers of the Daily Inn Hotel, Jakarta, that served by Food and Beverage Department during March 2019. The samples in this study were calcuated by Slovin Formula, with $10 \%$ error tolerance. The data then were processed by SPSS statistical analysis. The results of this study indicated that service quality had an effect on consumer satisfaction by 0.838 or $83.8 \%$ based on the coefficient of determination of 0.162 or $16.2 \%$ explained by other factors not included in this study. From the results of the T-test carried out, with the results of the analysis of 21.660 greater than 1.662 and $a$ probability of 0.000 smaller than 0.60 , it was concluded that $\mathrm{HO}$ was rejected and $H 1$ was accepted which means that the service quality variable $(X)$ significantly affects the consumer satisfaction variable $(Y)$.

\section{Pendahuluan}

Dunia perhotelan merupakan salah satu bisnis yang terus berkembang seiring dengan bekembangnya industri pariwisata. Semakin banyak wisatawan yang melakukan perjalanan wisata membuat tuntutannya terhadap akomodasi semakin tinggi. Kini hotel tidak hanya sekedar sebagai tempat menginap, wisatawan juga menginginkan variasi dalam jenis, karakteristik, pelayanan ataupun fasilitas yang tersedia. Tak heran bisnis hotel pun berkembang pesat. Jumlah Tingkat Penghunian Kamar (TPK) hotel bintang di Jakarta pada tahun 2018 sebesar 68,23\%, meningkat dibandingkan pada tahun 2017 yang jumlahnya 63.39\%. Di DKI Jakarta jumlah hotel berbintang, yaitu 232 hotel (Sumber: Dinas Pariwisata dan Kebudayaan DKI Jakarta, 2018).

Semua kebutuhan pelayanan makanan, minuman, dan kebutuhan lain yang terkait, dari para tamu yang menginap maupun yang tidak menginap di hotel biasanya dikelola oleh Food and Beverage Department. Oleh sebab itu departemen ini memegang peranan penting dalam bisnis perhotelan. Baik buruknya, berhasil tidaknya, serta dan populer tidaknya suatu hotel, salah satunya dipengaruhi oleh Food and Beverage Service (FBS) yang diberikan oleh Food and Beverage Department.

Kini, setiap perusahaan - khususnya yang bergerak di bidang jasa, seperti bisnis hotel - akan menempatkan kepuasan konsumen sebagai prioritas. Bahkan beberapa tahun terakhir ini diselenggarakan Indonesian Customer Stasifaction Award (ICSA) 
untuk memberikan penghargaan kepada perusahaan-perusahaan yang mampu mengutamakan kepuasan konsumen dalam menjalankan bisnisnya. Hal ini membuat keberhasilan bisnis dan tujuan perusahaan ditentukan salah satunya oleh kualitas pelayanan (service quality), terutama untuk perhotelan di Kota Jakarta yang harus saling berlomba menarik perhatian wisatawan.

Sebagai salah satu hotel berbintang di Jakarta, Hotel Daily Inn juga perlu memberikan kualitas pelayanan yang terbaik dan memuaskan kepada tamu. Pelayanan yang baik akan memberikan kepuasan dan loyalitas dari para konsumen.. Dalam menjalankan bisnisnya, Food and Beverage Department di Hotel Daily Inn harus berupaya untuk mencari tahu kebutuhan dan keinginan dari konsumennya sehingga dapat memberikan pelayanan yang tetap dan sesuai yang diharapkan.

Menyadari hal tersebut, memahami faktor apa saja yang dapat memengaruhi kepuasan konsumen merupakan salah satu indikator penting yang menentukan keberhasilan sebuah bisnis, termasuk bisnis hotel. Sebagai contoh, Hotel Daily Inn, Jakarta, merupakan hotel baru, maka Hotel Daily Inn, Jakarta, ingin mengetahui apakah kualitas pelayanan Food and Beverage Department -nya sudah memuaskan konsumen sehingga konsumen datang kembali atau mengunakan jasa Hotel Daily Inn, Jakarta.

Berdasarkan alasan tersebut, peneliti tertarik untuk meneliti tentang "Seberapa besar pengaruh kualitas pelayanan Food and Beverage Department terhadap kepuasan konsumen di Hotel Daily Inn, Jakarta?"

\subsection{Hotel}

Adanya kebutuhan sebagai sarana akomodasi saat melakukan perjalanan wisata merupakan alasan mendasar semakin berkembangnya bisnis perhotelan, khususnya di daerah wisata ataupun daerah pusat bisnis, seperti Jakarta.. Hotel berasal dari bahasa latin, yakni "hospes" yang mempunyai pengertian untuk menunjukan orang asing yang menginap di rumah seseorang kemudian berkembang menjadi kata "hotel" yang dinyatakan sebagai rumah penginapan.

Hotel tak hanya sebagai tempat untuk menginap, tetapi juga menyediakan fasilitas untuk menikmati makan, minum, serta jasa-jasa lainnya yang dikelola secara profesionl. Menurut Rumekso (2001) hotel adalah bangunan yang menyediakan kamar untuk tempat menginap para tamu, makanan dan minuman, serta fasilitas-fasilitas lain yang diperlukan untuk mendapatkan keuntungan.

Sedangkan menurut I Gusti Bagus (2016) hotel adalah suatu usaha akomodasi dengan menyediakan pelayanan penginapan, makanan, minuman, dan fasilitas lainnya, yang dikelola secara profesional guna mendapatkan keuntungan Menurut Peraturan Menteri Pariwisata Indonesia, Nomor: PM.106/PW.006/MPEK/20112011, tentang Sistem Manajemen Pengamanan Hotel menyatakan bahwa hotel adalah penyediaan akomodasi secara harian berupa kamar-kamar di dalam 1 (satu) bangunan, yang dapat dilengkapi dengan jasa pelayanan makanan dan minuman, kegiatan hiburan serta fasilitas lainnya.

\subsection{Kualitas Pelayanan}

Pada dasarnya, kualitas pelayanan berupaya untuk memenuhi kebutuhan dan keinginan pelanggan dengan pelayanan yang sesuai dengan harapan konsumen. Dalam sebuah bisnis, kepuasan pelanggan menjadi salah satu kunci keberhasilan suatu usaha. Dengan memuaskan konsumen, organisasi dapat meningkatkan tingkat keuntungannya dan mendapatkan pangsa pasar yang lebih luas (Barsky, 1992) 
Dalam salah satu studi mengenai kualitas pelayanan oleh Parasuraman (1988) yang melibatkan 800 pelanggan (yang terbagi dalam empat perusahaan) berusia 25 tahun ke atas, disimpulkan bahwa terdapat lima dimensi kualitas pelayanan (Tjiptono, Chandra dan Adriana:2008), sebagai berikut:

1. Berwujud (Tangible) Terkait dengan penampilan dan sarana dan prasarana fisik yang diberikan oleh para pemberi jasa. Misalnya, gedung, perlengkapan dan peralatan yang digunakan (teknologi), kebersihan dan kerapihan penampilan petugas/pegawai.

2. Keandalan ((Reliability) Terkait dengan pemberian pelayanan secara akurat dan terpercaya. Seperti ketepatan waktu, akurasi yang tinggi, pelayanan yang sama untuk semua pelanggan tanpa kesalahan, sikap yang simpatik.

3. Ketanggapan (Responsiveness) Terkait kebijakan untuk membantu dan memberikan pelayanan yang cepat (responsive) dan tepat kepada pelanggan, termasuk juga penyampaian informasi yang jelas.

4. Jaminan dan Kepastian (Assurance). Terkait dengan kompetensi, pengetahuan, dan kemampuan para pegawai yang menimbulkan rasa percaya dan aman pada diri konsumen. Termasuk didalamnya, antara lain adalah komunikasi (communication), kredibilitas (credibility), keamanan (security), kompetensi (competence) dan sopan santun (courtesy).

5. Empati (Empathy) Terkait perhatian tulus yang diberikan kepada para konsumen. Tiap perusahaan diharapkan memiliki pengertian dan pengetahuan tentang pelanggan, memahami kebutuhan pelanggan secara spesifik, serta memilki waktu pengoperasian yang nyaman bagi pelanggan.

\subsection{Kepuasan Konsumen}

Kepuasan konsumen merupakan tujuan akhir dari suatu bisnis. Pelanggan yang puas merupakan aset besar bagi perusahaan, karena pelanggan yang puas biasanya akan menjadi loyal. Kualitas pelayanan yang dikelola dengan baik akan memberikan kepuasan konsumen yang akan diikuti dengan loyalitas.

Menurut Kotler dan Keller (2009) mempertahankan pelangan merupakan hal penting. Oleh karena itu terdapat 5 dimensi untuk mengukur kepuasan konsumen yaitu:

1. Membeli lagi.

2. Mengatakan hal-hal yang baik tentang perusahaan kepada orang lain dan merekomendasikan.

3. Kurang memperhatikan merek dan iklan produk pesaing.

4. Membeli produk lain dari perusahaan yang sama.

5. Menawarkan ide produk atau jasa kepada perusahaan.

\section{Metode Penelitian}

Penelitian ini merupakan penelitian kuantitatif dengan kualitas pelayanan sebagai variabel $\mathrm{X}$ dan kepuasan konsumen sebagai variabel Y. Penelitian ini dilakukan untuk mengetahui dan membuktikan hubungan antara pengaruh kualitas pelayanan Food and Beverage Department terhadap kepuasan konsumen di Hotel Daily Inn, Jakarta, dengan hipotesis sebagai berikut:

H0 = Tidak terdapat pengaruh kualitas pelayanan Food and Beverage Department terhadap kepuasan konsumen Hotel Daily Inn, Jakarta

H1 = Terdapat pengaruh kualitas pelayanan Food and Beverage Department terhadap kepuasan konsumen Hotel Daily Inn, Jakarta. 


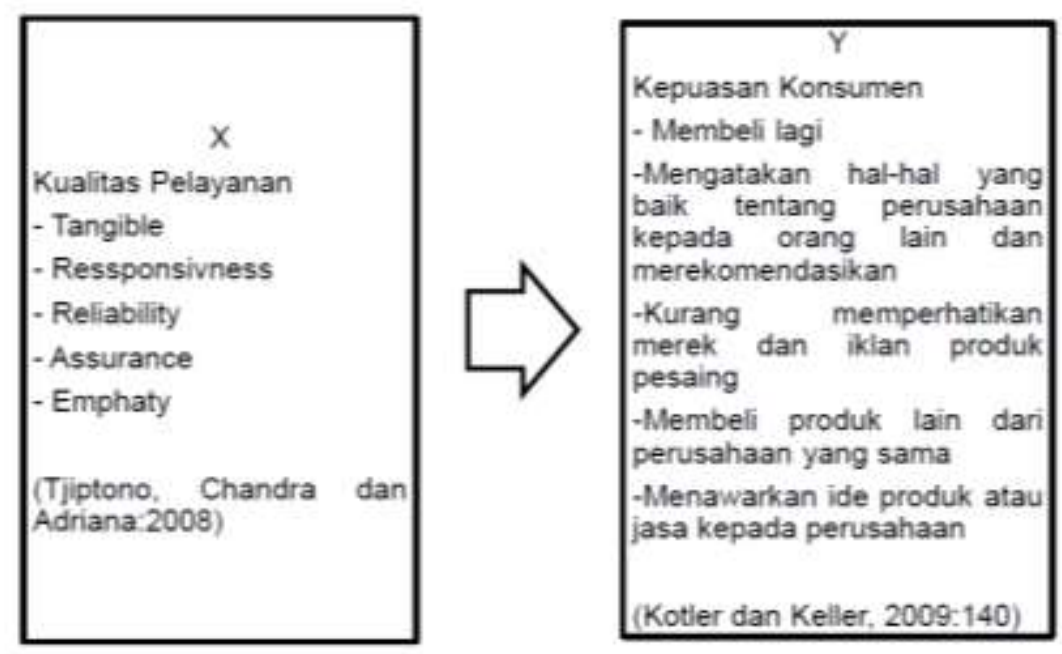

Gambar 1. Kerangka Teori

Sumber data yang digunakan ada 2, yaitu data primer dan sekunder. Data primer didapat secara langsung dari responden yang mengisi kuesioner di lokasi penelitian. Populasi sebesar 1.344 diambil dari jumlah konsumen yang menikmati pelayanan Food and Beverage Department, selama menginap di Hotel Daily Inn, Jakarta, selama bulan Maret 2019. Jumlah sampel sebesar 93 orang dihitung menggunakan Rumus Slovin dengan error percentage sebesar $10 \%$.

Kuesioner menggunakan tipe pengukuran bertingkat dengan Skala Likert. Rentang yang digunakan untuk mengukur derajat sangat tidak baik atau sangat baik untuk indikator variabel dalam penelitian ini adalah 1 (satu) sampai 5 (lima), yaitu dengan tingkat pembobotan sebagai berikut:

1. Jawaban sangat tidak setuju bobot nilai 1;

2. Jawaban tidak setuju, bobot nilai 2;

3. Jawaban kurang setuju, bobot nilai 3;

4. Jawaban setuju, bobot nilai 4;

5. Jawaban sangat setuju, bobot nilai 5

Bobot nilai ini kemudian diinterpretasikan menggunakan skala interval. Selanjutnya interval kriteria adalah sebesar 0,80 sehingga dari ketentuan tersebut, maka kriteria penilaian adalah:

- Jika nilai antara $1.00-1.80$ berarti kriteria sangat tidak baik

- Jika nilai antara $1.81-2.60$ berarti kriteria kurang baik

- Jika nilai antara $2.61-3.40$ berarti kriteria cukup baik

- Jika nilai antara $3.41-4.20$ berarti kriteria baik

- Jika nilai antara $4.21-5.00$ berarti kriteria sangat baik

Sedangkan data sekunder diperoleh dari penelitian yang dilakukan dengan cara mempelajari, meneliti dan mengkaji beberapa buku literatur, jurnal, majalah, situs web dan penelitian-penelitian terdahulu yang berhubungan dengan permasalahan yang sedang diteliti dan selanjutnya diolah kembali yang bertujuan untuk mendukung penelitian ini.

\section{Pembahasan}

Berdasarkan olah data kuesioner dari para responden, berikut hasil rekapitulasi variabel kualitas pelayanan: 
Tabel 1. Rekapitulasi Variabel Kualitas Pelayanan (X)

\begin{tabular}{|c|c|c|c|}
\hline No & Indikator & Nilai & Interprestasi \\
\hline 1 & $\begin{array}{l}\text { Fasilitas Food and Beverage } \\
\text { Department Hotel Daily Inn yang } \\
\text { ada terlihat rapi. }\end{array}$ & 4.20 & Baik \\
\hline 2 & $\begin{array}{l}\text { Kondisi sarana dan prasarana Food } \\
\text { and Beverage Department dalam } \\
\text { keadaan bersih. }\end{array}$ & 4.15 & Baik \\
\hline 3 & $\begin{array}{l}\text { Karyawan Food and Beverage } \\
\text { Department memberikan respon } \\
\text { terhadap kebutuhan konsumen }\end{array}$ & 4.17 & Baik \\
\hline 4 & $\begin{array}{l}\text { Pelayanan Food and Beverage } \\
\text { Department Hotel Daily Inn Jakarta } \\
\text { baik. }\end{array}$ & 4.17 & Baik \\
\hline 5 & $\begin{array}{l}\text { Karyawan Food and Beverage } \\
\text { Department cepat, tanggap dalam } \\
\text { mengatasi masalah dan keluhan } \\
\text { konsumen. }\end{array}$ & 4.11 & Baik \\
\hline 6 & $\begin{array}{l}\text { Karyawan memiliki kemauan untuk } \\
\text { memenuhi permintaan pelanggan } \\
\text { dengan cepat. }\end{array}$ & 4.07 & Baik \\
\hline 7 & $\begin{array}{l}\text { Makanan yang disajikan oleh } \\
\text { karyawan Food and Beverage } \\
\text { Department aman untuk dimakan. }\end{array}$ & 4.27 & Sangat Baik \\
\hline 8 & $\begin{array}{l}\text { Bahan-bahan makanan dan minuman } \\
\text { yang bersih dan segar. }\end{array}$ & 4.20 & Baik \\
\hline 9 & $\begin{array}{l}\text { Memberikan perhatian khusus } \\
\text { terhadap konsumen. }\end{array}$ & 3.98 & Baik \\
\hline 10 & $\begin{array}{l}\text { Konsumen dan karyawan menjalin } \\
\text { hubungan baik }\end{array}$ & 4.02 & Baik \\
\hline \multicolumn{2}{|c|}{$\begin{array}{l}\text { Rata-rata penafsiran }=41.34 / 10 \\
=4.134\end{array}$} & 41.34 & Baik \\
\hline
\end{tabular}

Dari Tabel 1 di atas dapat dilihat bahwa untuk secara umum seluruh indikator dinilai Baik, dengan nilai tertinggi diperoleh oleh indikator makanan yang disajikan oleh karyawan Food and Beverage Department aman untuk dimakan dengan jumlah 4.27 dan nilai terendah diperoleh oleh indikator memberikan perhatian khusus terhadap konsumen dengan jumlah 3.98.

Namun, dengan angka rata-rata penafsiran untuk Variabel Kualitas Pelayanan sebesar 4,13 dan angka tersebut termasuk dalam skala 3.41 - 4.20 dengan kriteria penilaian Baik. Sedangkan hasil rekapitulasi variabel kepuasan pelanggan adalah sebagai berikut: 
Tabel 2. Rekapitulasi Variabel Kepuasan Konsumen (Y)

\begin{tabular}{|c|c|c|c|}
\hline No & Indikator & Nilai & Interprestasi \\
\hline 1 & $\begin{array}{l}\text { Setelah mendapatkan pelayanan } \\
\text { Food and Beverage Department } \\
\text { konsumen merasa puas dengan } \\
\text { pelayanan yang diberikan. }\end{array}$ & 4.13 & Baik \\
\hline 2 & $\begin{array}{l}\text { Berminat untuk mengunjungi } \\
\text { kembali. }\end{array}$ & 4.04 & Baik \\
\hline 3 & $\begin{array}{l}\text { Konsumen akan kembali } \\
\text { menggunakan jasa Hotel Daily Inn } \\
\text { Jakarta. }\end{array}$ & 4.10 & Baik \\
\hline 4 & $\begin{array}{l}\text { Saya bersedia mempromosikan } \\
\text { prodak dan jasa yang ada di Hotel } \\
\text { Daily Inn Jakarta. }\end{array}$ & 3.82 & Baik \\
\hline 5 & $\begin{array}{l}\text { Saya bersedia memberikan } \\
\text { informasi tentang Hotel Daily Inn } \\
\text { Jakarta. }\end{array}$ & 4.04 & Baik \\
\hline 6 & $\begin{array}{l}\text { Saya bersedia merekomendasikan } \\
\text { kepada orang lain tentang } \\
\text { pelayanan yang ada di Hotel Daily } \\
\text { Inn Jakarta. }\end{array}$ & 4.04 & Baik \\
\hline 7 & $\begin{array}{l}\text { Saya percaya terhadap pelayanan } \\
\text { yang diberikan Hotel Daily Inn } \\
\text { Jakarta. }\end{array}$ & 3.81 & Baik \\
\hline 8 & $\begin{array}{l}\text { Saya tetap menggunakan jasa Hotel } \\
\text { Daily Inn walau ada bujukan (harga } \\
\text { dan pelayanan) dari hotel lainnya. }\end{array}$ & 3.98 & Baik \\
\hline 9 & $\begin{array}{l}\text { Saya akan menggunakan pelayanan } \\
\text { jasa lainnya di Hotel Daily Inn } \\
\text { seperti meeting room. }\end{array}$ & 3.98 & Baik \\
\hline 10 & $\begin{array}{l}\text { Saya berminat menggunakan paket } \\
\text { yang unik seperti ulang tahun, dan } \\
\text { lain-lainnya selama } 3-6 \text { bulan } \\
\text { sekali. }\end{array}$ & 5.02 & Sangat Baik \\
\hline \multicolumn{2}{|c|}{$\begin{array}{l}\text { Rata-rata penafsiran }=40.96 / 10 \\
=4,096\end{array}$} & 40.96 & Baik \\
\hline
\end{tabular}

Dari Tabel 2 di atas dapat dilihat bahwa secara umum semua indikator dinilai Baik, dengan nilai tertinggi di peroleh oleh indikator saya berminat menggunakan paket yang unik seperti ulang tahun, dan lain-lainnya selama 3 - 6 bulan sekali dengan jumlah 5.02 dan nilai terendah diperoleh oleh indikator saya percaya terhadap pelayanan yang diberikan Hotel Daily Inn Jakarta dengan jumlah 3.81.

Dengan nilai rata-rata penafsiran sebesar 4,096 dan angka tersebut termasuk dalam skala 3.41 - 4.20 dengan kriteria penilaian Baik. Sehingga dapat diketahui secara rata-rata bahwa kualitas pelayanan Food and Beverage Department Hotel Daily Inn, Jakarta, dinilai baik dalam memberikan kepuasan pada konsumen.

Uji hipotesis yang terdiri dari Uji Koefisien Determinasi, Regresi Linier Sederhana dan Uji T juga dilakukan untuk melihat pengaruh variabel X terhadap Y. Dan hasil uji tersebut peneliti mendapatkan hasil uji hipotesis $X$ menunjukan bahwa nilai t hitung sebesar 21,660 $>\mathrm{t}$ tabel 1.662 dengan tingkat signifikansi sebesar 0,000. Dari hasil tersebut dapat 
disimpulkan bahwa variabel kualitas pelayanan berpengaruh secara signifikan terhadap kepuasan konsumen.

Kualitas pelayanan yang meliputi: bukti langung (tangible), daya tanggap (responsiveness), keandalan (reliability), jaminan (assurance), dan empati (empathy) berpengaruh sebesar 0,838 atau $83,8 \%$ terhadap kepuasan konsumen. Sedangkan sisanya sebesar 0,162 atau 16,2\% dijelaskan oleh faktor-faktor lain yang tidak dimasukkan dalam penelitian ini. Hasil tersebut diperoleh peneliti saat melakukan pengujian koefisien determinasi untuk mengetahui kemampuan variabel independen yaitu kualitas pelayanan dalam menjelaskan variabel dependen yaitu kepuasan konsumen.

\section{Kesimpulan dan Saran}

Hasil penelitian menunjukkan bahwa kualitas pelayanan yang dilakukan Food and Beverage Department Hotel Daily Inn, Jakarta, berpengaruh secara signifikan terhadap kepuasan konsumen yang datang. Dengan hasil tersebut dapat disimpulkan bahwa H0 ditolak dan $\mathrm{H} 1$ diterima.

Hasil penelitian ini memberikan makna bahwa kualitas pelayanan merupakan suatu pendekatan yang tepat untuk dapat membantu manajemen dalam mencapai kepuasan konsumen. Sebagai salah satu bagian dari industri pariwisata yang sangat mengandalkan kekuatan pelayanan (service), maka kepuasan pelanggan yang menikmati jasa Food and Beverage Department di Hotel Daily Inn, Jakarta, harus menjadi prioritas.

Saran bagi manajemen Hotel Daily Inn, Jakarta, khususnya Food and Beverage Department adalah untuk lebih memberi perhatian khusus kepada indikator-indikator dalam penelitian yang masih memiliki nilai penafsiran di bawah rata-rata. Tujuannya tentu agar konsumen yang datang bisa mendapatkan kepuasan maksimal.

\section{Daftar Pustaka}

Barsky, Jonathan. 1992. Customer Satisfaction in the Hotel Industry: Measurement and Meaning. Cornell H.R.A. Quartery, 7, 20-41.

I Gusti Bagus, Rai Utama. 2016. Pemasaran Pariwisata. Yogyakarta: Penerbit CV Andi.

Kotler, Philip, dan Kevin Lane Keller. 2009. Manajemen Pemasaran Jilid 2, edisi Ketiga Belas, Terjemahan Bob Sabran, MM. Jakarta: Penerbit Erlangga.

Rumekso. 2001. Housekeeping SMK. Bandung: CV Armico Offset.

Tjiptono, Fandy, Gregorius Chandra dan Dadi Adriana. 2008. Pemasaran Strategik. Yogyakarta: Andi. 